\title{
Tumor Suppressor Functions of miRNA-375 in Nasopharyngeal Carcinoma through Inhibition of Ubiquitin-Specific Protease 1 Expression
}

\section{Xu Jiayuan}

The Third Affiliated Hospital of Wenzhou Medical University

\section{Li Bangliang}

The Third Affiliated Hospital of Wenzhou Medical University

\section{Song Wei}

the third affiliated hospital of Wenzhou Medical University

\section{Cao Longhe}

the third affiliated hospital of Wenzhou Medical University

\section{Zhu Chuansai}

the third affiliated hospital of Wenzhou Medical University

Lin Sen ( $\square$ Inns@163.com )

the third Affiliated Hospital of Wenzhou Medical University https://orcid.org/0000-0002-1175-0232

\section{Primary research}

Keywords: Nasopharyngeal carcinoma, USP1, miR-375, PI3K/AKT pathway

Posted Date: August 4th, 2021

DOI: https://doi.org/10.21203/rs.3.rs-533217/v1

License: (c) (1) This work is licensed under a Creative Commons Attribution 4.0 International License. Read Full License 


\section{Abstract}

Background: Nasopharyngeal carcinoma (NPC) development involves many genetic alterations. This study profiled differentially expressed miRNAs and selected miR-375 for further study.

Methods: Differentially expressed miRNAs (DE-miRNAs) were screened using online databases and subjected to various analyses. miR-375 mimics with negative control cDNA, and ubiquitin-specific protease 1 (USP1) as well as a vector-only control were transfected into NPC cells for analysis by quantitative PCR, western blotting, wound healing, Transwell, cell viability, flow cytometry, and luciferase gene reporter assays.

Results: A total of 308 NPC and 23 normal tissues were analyzed, and 67 DE-miRNAs were identified. Among these, miR-375 was downregulated and miR-21-5p was upregulated. Bioinformatical analysis identified USP1 as a potential target gene of miR-375. Furthermore, miR-375 expression was decreased, whereas USP1 expression was increased in NPC. Increased USP1 expression was associated with poor survival of head and neck cancer patients. The luciferase assay confirmed miR-375 binding to the USP1 3'-untranslated region (UTR), while the transfection experiment confirmed miR-375 expression reduced USP1 expression, and USP1 overexpression reversed the anti-tumor activity of miR-375 in NPC cells, determined by tumor cell migration, invasion, apoptosis, and gene expression. In addition, USP1 overexpression activated phosphoinositide 3-kinase (PI3K) signaling, whereas a selective PI3K inhibitor (S2793) could reverse the effects of USP1 on NPC cells in vitro.

Conclusions: This study confirmed decreased miR-375 expression and increased miR-21 expression in NPC tissues. Downregulated miR-375 expression led to USP1 upregulation, which in turn activated PI3K/Akt signaling and promoted NPC cell migration and invasion, but inhibited NPC cell apoptosis.

\section{Introduction}

Nasopharyngeal carcinoma (NPC), the most common cancer originating in the nasopharynx, differs significantly from other head and neck cancers in terms of risk factors, pathogenesis, clinicopathological characteristics, and treatment options [1]. Global cancer statistics have estimated that more than 133,000 new NPC cases and more than 80,000 NPC cancer-related deaths occurred in 2020 across the globe, accounting for $0.7 \%$ and $0.8 \%$ of all cancer incidence and death, respectively [2]. The majority of NPC patients are geographically localized to Southeast Asia, while China has the highest incidence and mortality rates[3; 4]. NPC risk factors include viral infections, environmental influences, and genetic factors, but infection with Epstein-Barr virus (EBV) is one of the primary risk factors for the development of NPC[5]. Activation of nuclear factor-kappa B (NF-kB) signaling has been shown in approximately $50 \%$ of NPC cases [6; 7]. Clinically, NPC patients can be treated with surgery, chemotherapy, radiotherapy, and immune-based therapy[8]. However, the development of more effective treatments for NPC is urgently needed.

microRNA (miRNA) is a class of small non-coding RNA molecules in the human genome that can regulate gene expression by directly binding to the 3'-untranslated region (UTR) of target genes to exert a biological effect on a cell [9]. miRNAs have been reported to play an important role in various human cancers[10]. In NPC, recent studies have shown that exosomal miRNA-301a-3p expression was able to promote NPC cell proliferation and invasion [11], miRNAs derived from circulating small extracellular vesicles could be used to diagnose early NPC [12], and EBVencoded miRNA BART 8-3p was able to enhance NPC radioresistance-associated metastasis[13]. In this regard, further bioinformatical analysis into the involvement of miRNAs in NPC could allow for an in-depth investigation of NPC genetic data using various online databases. Thus, miRNAs that are related to NPC were screened and assessed 
using data from the Gene Expression Omnibus (GEO) database and further bioinformatical analyses were performed including miRNA-gene targeting, gene ontology (GO), Kyoto Encyclopedia of Genes and Genomes (KEGG) pathway, and protein-protein interaction (PPI) network analyses. The NPC-related differentially expressed miRNAs (DEmiRNAs) and the underlying mechanisms by which these DE-miRNAs could play a role in the development and progression of NPC were explored. Additionally, a series of experiments were performed to verify the data obtained from the above bioinformatics analysis.

\section{Materials And Methods}

\section{Bioinformatical analysis}

In this study, miRNA data from NPC samples were first screened and downloaded from the GEO database (https://www.ncbi.nlm.nih.gov/geo/index.cgi?qb=dat). GEO 2R data were selected due to the differentially expressed miRNAs in NPC, and the adjusted $p$-value (0.05) and fold change (2) cutoffs were set to obtain expression levels using the University of Alabama Cancer Database (UALCAN)[14]. A volcano map was plotted, and survival analysis was performed using GEO $2 \mathrm{R}$ and OncomiR, respectively. Next, the target genes of the miRNAs were analyzed using the miRtarBase[15] and TargetScan [16] tools. In addition, GO enrichment, pathway enrichment, PPI network analysis, and hub gene analyses were also performed using Metascape, the String database, and Cytoscape (version 3.8).

\section{Clinical samples}

A total of 25 NPC patients and age-matched healthy controls were recruited from The Third Affiliated Hospital of Wenzhou Medical University (Wenzhou, China) between March 2001 and March 2020. The patients were histologically diagnosed with NPC using the Head and Neck Tumor (HNT) classification published by the World Health Organization (WHO) in 2017[17]. All patients had not received any radiotherapy or chemotherapy before surgery. Tumor tissues and normal nasal mucosa tissues from healthy controls were collected and stored at $-80^{\circ} \mathrm{C}$ until subsequent use for polymerase chain reaction (PCR)-based detection of gene expression.

This study was approved by the Ethics Committee of Wenzhou Medical University and all participants provided written informed consent prior to study enrollment.

\section{Cell culture and transfection}

Cell lines including CNE-1 (highly differentiated nasopharyngeal squamous cell carcinoma), CNE-2 and HNE-1 (poorly differentiated nasopharyngeal squamous cell carcinoma), as well as human nasal mucosal epithelial NP69 cells were originally obtained from Runxin Bio. (Suzhou, China) and maintained in Dulbecco's modified Eagle medium (DMEM) supplemented with $2 \mathrm{~mL}$ glutamine, $0.1 \mathrm{~mL}$ non-essential amino acids, $10 \%$ fetal bovine serum (FBS), and $1 \%$ penicillin/streptomycin in a humidified incubator with $5 \% \mathrm{CO}_{2}$ at $37^{\circ} \mathrm{C}$. When the cells were approximately $80 \%$ confluent, they were collected for western blot analysis.

The pcDNA3.1 plasmid carrying the USP1 coding sequencing (CDS; pcDNA3.1-USP1) was obtained from Zhejiang Gloucester Biotechnology Company (Hangzhou, China) and the miR-375 mimics and negative control (NC) were from Thermo Fisher Scientific (Waltham, MA, USA). For gene transfection, cells were grown in a 96-well plate overnight and then transfected for $24 \mathrm{~h}$ with pcDNA3.1-USP1, vector-only control, miR-375 mimics, or a NC using Lipofectamine 2000 (Thermo Fisher Scientific, Waltham, MA, USA) following the manufacturer's instructions. After the transfection, cells were harvested for further experiments.

Transwell invasion assay 
According to the manufacturer's instructions, Transwell chambers pre-coated with Matrigel (pore size of $8 \mu \mathrm{m}$; Corning Inc., Corning, NY, USA) were set to include post-transfection CNE1 cells $\left(5 \times 10^{4}\right)$ suspended in serum-free medium in the upper chamber, whereas the lower chamber was filled with FBS-containing medium. After $48 \mathrm{~h}$ in culture, the cells remaining on the top surface of the membrane were removed and the cells that had invaded onto the bottom of the membrane were stained with crystal violet and counted using a DMi8 optical microscope (Leica; Weztlar, Germany).

\section{Wound healing assay}

After the $24 \mathrm{~h}$ transfection, CNE1 cells were inoculated into six-well plates $\left(4 \times 10^{5}\right.$ cells/well) and cultured for $24 \mathrm{~h}$ to reach $100 \%$ confluency. Using a sterile $200-\mu \mathrm{L}$ pipette, the cell monolayer was wounded, and cells were further cultured for $48 \mathrm{~h}$. The wounds were measured using a DMi8 optical microscope and the cell migration rate was calculated using the following equation: (width at $0 \mathrm{~h}$ - width at $48 \mathrm{~h}$ ) / width at $0 \mathrm{~h}$.

\section{Flow cytometry}

After the transfection, cells were subjected to an Annexin V-fluorescein isothiocyanate (FITC) apoptosis assay using the Annexin V-FITC Apoptosis Detection Kit from Thermo Fisher Scientific. In brief, CNE1 cells were grown and transfected with pcDNA3.1-USP1, vector-only control, miR-375 mimics, or the NC using Lipofectamine 2000 (Thermo Fisher Scientific) for $48 \mathrm{~h}$. After the transfection, cells were harvested and subjected to Annexin V-FITC and propidium iodide $(\mathrm{PI})$ staining according to the manufacturer's instructions. Finally, after a 5 min incubation at room temperature in the dark, the apoptosis rate of cells was analyzed using a flow cytometer (Becton Dickinson FACS Vantage SE, USA).

\section{Western blot}

After the $24 \mathrm{~h}$ transfection, CNE1 cells were harvested for extraction of total cellular protein using radioimmunoprecipitation assay (RIPA) lysis buffer. The cell lysate was then centrifuged, supernatant was collected and mixed with the sample buffer, and the mixture was boiled for $5 \mathrm{~min}$. Equal amounts of protein were subjected to sodium dodecyl sulfate-polyacrylamide gel electrophoresis (SDS-PAGE) and transferred to a nitrocellulose membrane (Thermo Fisher Scientific). For protein blotting, the membranes were first blocked in $5 \%$ skim milk in phosphate buffered saline (PBS)-Tween 20 (PBS-T) for $1 \mathrm{~h}$ at the room temperature, then incubated with diluted primary antibodies of anti-USP1 (Fine biotech, Wuhan, China), c-Myc (Huabio, Hangzhou, China), Bad (Bioyotime Technology, Shanghai, China), Bax (Biolab Technology, Xian, China), Bcl-2 (Hengyuan Biological, Shanghai, China), phosphoinositide 3-kinase (PI3K; Biolab Technology, Xian, China), phospho-PI3K (p-PI3K; Bioworld Technology, Bloomington, USA), caspase-3 (Biolab Technology, Xian, China), E-cadherin (Huabio, Hangzhou, China), Akt (Huabio, Hangzhou, China), or p-Akt (Bioworld Technology, Bloomington, USA) at $4^{\circ} \mathrm{C}$ overnight. The following day,

membranes were washed $3 x$ with PBS-T and then incubated with a horseradish peroxidase (HRP)-conjugated second antibody (Thermo Fisher Scientific, Waltham, MA, USA) for $1 \mathrm{~h}$ at room temperature. After washing $3 \mathrm{x}$ with PBS-T, the membranes were subjected to an incubation with enhanced chemiluminescence (ECL) reagents to detect the protein signal. Blots were observed on an ImageQuant LAS4000 biomolecular imager (General Electric Medical, Shanghai, China) to visualize protein expression. Experiments were repeated at least three times.

\section{Cell viability CCK-8 assay}

After the $24 \mathrm{~h}$ transfection, CNE1 cells $\left(1 \times 10^{4}\right)$ were inoculated into each well of a 96-well plate and then incubated for 48 h. Next, the CCK-8 reagent (10 $\mu$; MedChemExpress [MCE], Shanghai, China) was added to each well, and cells were incubated for $4 \mathrm{~h}$ according to the manufacturer's instructions. The cells were then used immediately for 
measurement of the optical density using a microplate reader at an absorbance of $490 \mathrm{~nm}$. The experimental conditions were performed in triplicate and repeated at least three times.

\section{Quantitative reverse transcription-polymerase chain reaction (qRT- PCR)}

Following the $24 \mathrm{~h}$ transfection, CNE1 cells and tissue specimens were subjected to RNA isolation using TRIzol (Thermo Fisher Scientific) and the RNA was reverse transcribed using M-MuLV reverse transcriptase (New England Biolabs, Beijing, China) using the ABI StepOne Plus system according to the manufacturers' instructions. Next, the cDNA samples were subjected to qPCR amplification using the maxima SYBR Green/ROX qPCR Master Mix according to the manufacturer's instructions. The primer sequences of genes were: 5'-TTT GTT CGT TCG GCT CGC3'(miR-375), 5'-ACU GGA CUU GGA GUC AGA AGG-3'(miR-375 mimics), and 5'-CTC CCG GGA TGT AGT TGG TG$3^{\prime}($ USP1). The amplified gene of interest was normalized to the relative level of glyceraldehyde 3-phosphate dehydrogenase (GAPDH) mRNA.

\section{Prediction of miRNA targets and dual-luciferase reporter assay}

miRNA targets were predicted using the miRtarBase [18] and TargetScan[16] tools. The luciferase reporter gene detection system was used to verify potential miRNA targets. Specifically, the putative 3'-UTR miRNA binding sequences were synthesized and cloned into the Spel and HindIII cloning sites of the pMIR-REPORT vector (Biolab Technology, Xian, China), while the USP1 3'-UTR containing miR-375 mutant sequences was synthesized by Eurofins genomics (Vienna, Austria) and the miR-375 binding site was mutated to construct mutant USP1, and the mutant (MUT)/wild type (WT) were cloned into the pMIR-REPORT vector between the Spel and HindIII sites. After DNA sequence confirmation, these constructs were co-transfected with the target miRNA and luciferase control plasmid into HEK293 reporter cells in a 48-well plate using Lipofectamine 2000. Plasmid DNA (0.2 $\mu \mathrm{g})$ and miRNA (100 $\mathrm{nmol} / \mathrm{L}$ ) were used for the transfection experiments, and subsequently the luciferase activity was measured $24 \mathrm{~h}$ after gene incubation using the luciferase reporter gene detection system (Biolab Technology) according to the manufacturer's instructions.

\section{Statistical analysis}

All experimental data were analyzed using GraphPad Prism (version 8.0; GraphPad Software, La Jolla, CA, USA) and SPSS (version 19.0; SPSS, Chicago, IL, USA). All data were collected from at least three independent experiments and expressed as the mean \pm standard deviation (SD). The difference between two groups was analyzed using the Student's $t$-test, while the Pearson correlation coefficient was used to analyze the correlation of gene expression. A $p$ value less than 0.05 indicated statistical significance.

\section{Results}

\section{Identification of differentially expressed miRNAs (DE-miRNAs)}

In this study, both the GSE 70970 dataset, which contained 246 NPC and 17 normal tissues, and the GSE 36682 dataset, which contained 62 NPC and six normal tissues, were used. After an initial analysis, 67 DE-miRNAs were obtained from these two datasets by applying the GEO $2 \mathrm{R}$ online tool for analysis ( $|\log \mathrm{FC}| \geq 1 ; p$-value $<0.05)$. Two common DE-miRNAs were then assessed further: down-regulated miR-375 ( $|\log F C|<0)$ and up-regulated miR-21-5p $(|\log \mathrm{FC}|>0)$. The volcano plots are shown in Fig. $1 \mathrm{~A}$ and $\mathrm{B}$, while Fig. $1 \mathrm{C}$ and $\mathrm{D}$ show the expression of miR-21 and miR-375 in head and neck squamous cell carcinoma (HNSCC) tissues vs. normal tissues using data from the 
UALCAN database. Figure $1 \mathrm{E}$ and $\mathrm{F}$ show the survival analyses stratified by miR-375 and miR-21 expression in NPC patients from the OncomiR database. Next, the detailed differential expression of miR-375 and miR-21 as well as the statistical data from GSE 36682 and GSE 70970 are shown in Table 1.

Table 1

Differential expression of miR-21 and miR-375 in nasopharyngeal carcinoma (NPC) vs. normal tissues using data from two different datasets.

\begin{tabular}{|llll|}
\hline & miRNA & Adj. $p$-value & Log fold change \\
\hline GSE 36682 & miR-21 & $8.31 \mathrm{e}-31$ & -1.643277 \\
\hline & miR-375 & $1.97 \mathrm{e}-04$ & 1.172213 \\
\hline GSE 70970 & miR-21 & $2.61 \mathrm{e}-08$ & -2.889119 \\
\hline & miR-375 & $2.32 \mathrm{e}-09$ & 4.0474 \\
\hline
\end{tabular}

\section{Bioinformatical data of miRNA targets, functions, and gene-gene interactions}

The StarBase and TargetScan Human 7.2 were used to predict potential target genes, and a total of 4491 potential genes were found. A Venn diagram was used to consider the accuracy of the biological analysis and evaluate genes closely related to the miRNAs and mRNAs, which identified 436 target genes. To investigate the effects of these genes at the molecular level, GO terms and the Kyoto Encyclopedia of Genes and Genomes (KEGG) pathway enrichment analysis were used to predict biological functions and related pathways among distinct differentially expressed genes (DEGs). Figure 2A shows the functions of genes related to cellular processes, the regulation of biological processes, and cellular component organization or biogenesis. These target genes were significantly enriched in vasculature development, response to growth factor, mesenchyme development, sensory system development, negative regulation of cell differentiation, mesodermal commitment pathway, mitogen-activated protein kinase signaling pathway and signaling by receptor tyrosine kinases (Fig. 2A). Figure $2 \mathrm{~B}$ and $\mathrm{C}$ show the result of the enrichment analysis and each term is represented by a circle node, where the size is proportional to the number of input genes that fall into that term, and the color represents the cluster identity (nodes of the same color belong to the same cluster). Furthermore, a PPI network analysis of these target genes was performed to confirm the connection of the network modules using MCODE. The enrichment analysis of each MCODE module pathway and process was applied independently and the data are shown in Fig. 2D and E.

\section{PPI network and miRNA-hub gene network data}

Cytoscape was used to draw the PPI network of the miR-375 and miR-21 target genes. The matching nodes of these target genes were constructed using the String database and the PPI network showed the importance of a gene that is positively correlated with the number of genes it may affect. Overall, 250 hub genes were identified according to node degree (Fig. 3A and B). Specifically, miR-375 could modulate 78 hub genes, while miR-21 could regulate 168 hub genes. This PPI network suggested that miR-375 and miR-21 might be the critical potential regulators in NPC. 
Next, the top 10 target genes for both miR-21 and miR-375 were selected (ranked by degree value, data shown in Table 2). Among these, genes with insufficient data were excluded e.g., tripartite motif containing 33(TRIM33) and genes with insignificant differences were excluded e.g., neurogenic locus notch homolog (NOTCH2). As such, genes with insignificant differences in survival curves were also excluded (i.e., G protein subunit gamma 12(GNG12), GATA zinc finger domain containing 2B(GATAD2B), YOD1 deubiquitinase (YOD1), Protein tyrosine phosphatase nonreceptor type 14(PTPN14), Fas ligand (FASLG), Heterogeneous nuclear(HNRNPU), SKI proto-oncogene(SKI), DnaJ heat shock protein family (DNAJC16), Eukaryotic translation initiation factor 4 gamma 3(EIF4G3), SERPINEI mRNA binding protein 1(SERBPI), ETS transcription factor ELK4(ELK4), ENAH actin regulator (ENAH), and Y-box binding protein 1(YBX1). Additionally, there was negative regulation between most miRNAs and their downstream target genes; therefore, genes with an expression not negatively correlated to miRNA levels were also excluded, such as S100 calcium binding protein A10(S100A10) and Nuclear factor I A(NFIA), resulting in the identification of USP1 with a potential tumor-inhibition role in NPC. Therefore, it was hypothesized that miR-375 might exert a tumor-suppressive effect by directly targeting USP1 expression. In this regard, USP1 expression was assessed in various cancer tissues using data from ONCOMINE and Gene Expression Profiling Interactive Analysis (GEPIA; Fig. 4A and B), and USP1 expression was associated with the survival of HNSSC patients using UALCAN data (Fig. 4C-G). More specifically, Fig. 4A shows USP1 expression in association with the prognosis of 16 types of cancer (GEPIA database), while Fig. 4B reveals USP1 expression in association with the prognosis of 15 types of cancer (ONCOMINE database). Figures $\mathrm{C}$ through $\mathrm{G}$ reveal data regarding the highest USP1 expression in stage IV, N4, and male NPC patients. 
Table 2

Top ten hub genes of miR-21 and miR-375 target genes.

\begin{tabular}{|c|c|c|c|c|c|c|c|c|c|}
\hline${ }_{21}^{\operatorname{miR}}-$ & $\begin{array}{l}\text { Gene } \\
\text { name }\end{array}$ & $\begin{array}{l}\text { Normal } \\
\text { vs. } \\
\text { Primary } \\
\text { (p- } \\
\text { value) }\end{array}$ & $\begin{array}{l}\text { Survival } \\
(p- \\
\text { value) }\end{array}$ & $\begin{array}{l}\text { Expression } \\
\text { (tumor) }\end{array}$ & $\begin{array}{l}\text { miR- } \\
375\end{array}$ & $\begin{array}{l}\text { Gene } \\
\text { name }\end{array}$ & $\begin{array}{l}\text { Normal } \\
\text { vs. } \\
\text { Primary } \\
\text { (p- } \\
\text { value) }\end{array}$ & $\begin{array}{l}\text { Survival } \\
(p- \\
\text { value })\end{array}$ & $\begin{array}{l}\text { Expression } \\
\text { (tumor) }\end{array}$ \\
\hline & GNG12 & $\begin{array}{l}1.14 \mathrm{E}- \\
03 \\
(p<0 \\
0.05)\end{array}$ & 0.640 & $\begin{array}{l}\text { Up- } \\
\text { regulated }\end{array}$ & & EIF4G3 & $\begin{array}{l}8.65 \mathrm{E}- \\
07 \\
(p<0 \\
0.05)\end{array}$ & 0.510 & $\begin{array}{l}\text { Up- } \\
\text { regulated }\end{array}$ \\
\hline & TRIM33 & NA & NA & NA & & SERBP1 & $\begin{array}{l}1.55 \mathrm{E}- \\
06 \\
(p<0 \\
0.05)\end{array}$ & 0.170 & $\begin{array}{l}\text { Up- } \\
\text { regulated }\end{array}$ \\
\hline & S100A10 & $\begin{array}{l}1.80 \mathrm{E}- \\
03 \\
(p<0 \\
0.05)\end{array}$ & 0.015 & $\begin{array}{l}\text { Up- } \\
\text { regulated }\end{array}$ & & NOTCH2 & $\begin{array}{l}6.79 \mathrm{E}- \\
01 \\
(p> \\
0.05)\end{array}$ & 0.360 & $\begin{array}{l}\text { Down- } \\
\text { regulated }\end{array}$ \\
\hline & GATAD2B & $\begin{array}{l}1.66 \mathrm{E}- \\
12 \\
(p<0 \\
0.05)\end{array}$ & 0.180 & $\begin{array}{l}\text { Up- } \\
\text { regulated }\end{array}$ & & ELK4 & $\begin{array}{l}1.62 \mathrm{E}- \\
12 \\
(p<0 \\
0.05)\end{array}$ & 0.350 & $\begin{array}{l}\text { Up- } \\
\text { regulated }\end{array}$ \\
\hline & YOD1 & $\begin{array}{l}4.78 \mathrm{E}- \\
02 \\
(p<0 \\
0.05)\end{array}$ & 0.390 & $\begin{array}{l}\text { Down- } \\
\text { regulated }\end{array}$ & & ENAH & $\begin{array}{l}<1 \mathrm{E}-12 \\
(p<0 \\
0.05)\end{array}$ & 0.940 & $\begin{array}{l}\text { Up- } \\
\text { regulated }\end{array}$ \\
\hline & PTPN14 & $\begin{array}{l}1.49 \mathrm{E}- \\
12 \\
(p<0 \\
.05)\end{array}$ & 0.710 & $\begin{array}{l}\text { Up- } \\
\text { regulated }\end{array}$ & & SKI & $\begin{array}{l}3.66 \mathrm{E}- \\
05 \\
(p<0 \\
0.05)\end{array}$ & 0.790 & $\begin{array}{l}\text { Up- } \\
\text { regulated }\end{array}$ \\
\hline & FASLG & $\begin{array}{l}1.84 \mathrm{E}- \\
10 \\
(p<0 \\
0.05)\end{array}$ & 0.110 & $\begin{array}{l}\text { Up- } \\
\text { regulated }\end{array}$ & & DNAJC16 & $\begin{array}{l}1.14 \mathrm{E}- \\
02 \\
(p<0 \\
0.05)\end{array}$ & 0.063 & $\begin{array}{l}\text { Up- } \\
\text { regulated }\end{array}$ \\
\hline & HNRNPU & $\begin{array}{l}4.63 \mathrm{E}- \\
14 \\
(p<0 \\
0.05)\end{array}$ & 0.640 & $\begin{array}{l}\text { Up- } \\
\text { regulated }\end{array}$ & & YBX1 & $\begin{array}{l}<1 \mathrm{E}-12 \\
(p<0 \\
0.05)\end{array}$ & 0.510 & $\begin{array}{l}\text { Up- } \\
\text { regulated }\end{array}$ \\
\hline & SKI & $\begin{array}{l}3.66 \mathrm{E}- \\
05 \\
(p<0 \\
0.05)\end{array}$ & 0.790 & $\begin{array}{l}\text { Up- } \\
\text { regulated }\end{array}$ & & NFIA & $\begin{array}{l}6.43 \mathrm{E}- \\
09 \\
(p<0 \\
0.05)\end{array}$ & 0.015 & $\begin{array}{l}\text { Down- } \\
\text { regulated }\end{array}$ \\
\hline
\end{tabular}




\begin{tabular}{|c|c|c|c|c|c|c|c|c|c|}
\hline${ }_{21}^{\operatorname{miR}-}$ & $\begin{array}{l}\text { Gene } \\
\text { name }\end{array}$ & $\begin{array}{l}\text { Normal } \\
\text { vs. } \\
\text { Primary } \\
\text { (p- } \\
\text { value) }\end{array}$ & $\begin{array}{l}\text { Survival } \\
(p- \\
\text { value) }\end{array}$ & $\begin{array}{l}\text { Expression } \\
\text { (tumor) }\end{array}$ & $\begin{array}{l}\text { miR- } \\
375\end{array}$ & $\begin{array}{l}\text { Gene } \\
\text { name }\end{array}$ & $\begin{array}{l}\text { Normal } \\
\text { vs. } \\
\text { Primary } \\
\text { (p- } \\
\text { value) }\end{array}$ & $\begin{array}{l}\text { Survival } \\
(p- \\
\text { value })\end{array}$ & $\begin{array}{l}\text { Expression } \\
\text { (tumor) }\end{array}$ \\
\hline & DNAJC16 & $\begin{array}{l}1.14 \mathrm{E}- \\
02 \\
(p<0 \\
0.05)\end{array}$ & 0.063 & $\begin{array}{l}\text { Up- } \\
\text { regulated }\end{array}$ & & USP1 & $\begin{array}{l}<1 \mathrm{E}-12 \\
(p<0 \\
0.05)\end{array}$ & 0.049 & $\begin{array}{l}\text { Up- } \\
\text { regulated }\end{array}$ \\
\hline
\end{tabular}

\section{Downregulation of miR-375 but upregulation of USP1 in NPC cells}

To confirm the role of miR-375 and USP1 in NPC development, their expression profiles were assessed using the ONCOMINE data, and USP1 was found to be overexpressed in various human cancers (Fig. 4C), whereas miR-375 expression was shown to be reduced in these cancers, indicating that miR-375 may possess anti-tumor activity in NPC (Fig. 1D). Next, qRT-PCR analysis revealed that compared to the normal cell line, miR-375 expression was downregulated in NPC cell lines, whereas USP1 expression was up-regulated in NPC cell lines (Fig. 5). Figures 5C through $\mathrm{F}$ also show that expression of miR-375, USP1, and the pathway proteins in CNE1 cells were significantly different. Therefore, CNE1 cells were chosen for the following experiments.

\section{miR-375 directly targets USP1 in NPC cells}

To confirm USP1 as a target gene of miR-375, a series of experiments were conducted. Expression of USP1 mRNA in CNE1 cells was remarkably upregulated, whereas miR-375 was downregulated, according to western blot and qRTPCR experiments, respectively. Moreover, a dual-luciferase reporter assay was performed, and luciferase activity was markedly lower in CNE1 cells co-transfected with the wild-type USP1 and miR-375 mimics compared to the control group, indicating that miR-375 negatively regulated USP1 expression in NPC by directly binding to the 3'-UTR of USP1.

\section{miR-375-mediated inhibition of NPC cell migration and invasion, and induction of NPC cell apoptosis in vitro}

To assess the effects of changes in miR-375 expression in NPC cells, various assays were performed. The data revealed that transfection of miR-375 mimics into CNE1 cells induced miR-375 expression compared to NC cells. The Transwell invasion and wound healing assays showed that upregulation of miR-375 expression enhanced NPC cell migration and invasion (Fig. 7A). The western blot data showed that invasion-related proteins, such as $\mathrm{N}$-cadherin, Snail and vimentin, were significantly decreased, but E-cadherin expression was upregulated following miR-375 expression in NPC cells (Fig. 7G). In contrast, NPC cell apoptosis was significantly increased after miR-375 mimic transfection compared to the NC and control groups (Fig. 7C). Western blot data showed that after transfection with miR-375 mimics, the level of cleaved caspase-3 (CCS-3), Bad, and Bax proteins was significantly increased, whereas the expression of c-Myc and Bcl-2 was significantly reduced (Fig. 7G). 


\section{USP1 promotion of NPC cell proliferation and invasion, and suppression of NPC cell apoptosis in vitro}

Next, the role of USP1 in NPC was determined by overexpression of USP1 protein in CNE1 cells. Compared to the NC and control groups, USP1 protein was upregulated in CNE1 cells (Fig. 7). Next, the Transwell and wound healing assays revealed that USP1 overexpression enhanced the capacity of NPC cells to invade and migrate compared to the vector-only-transfected NC cells (Fig. 7B and $\mathrm{H}$ ). Compared with the NC and control cells, the rate of apoptosis in CNE1 cells was significantly reduced after USP1 transfection (Fig. 7D). Western blot data showed that cell invasionrelated proteins ( $\mathrm{N}$-cadherin, Snail, and vimentin), as well as apoptosis-related proteins (c-Myc and Bcl-2) were significantly increased. Additionally, E-cadherin expression was significantly decreased and the levels of CCS-3, Bad, and Bax proteins were significantly reduced (Fig. 7G).

Furthermore, a rescue assay was performed by co-transfection of miR-375 mimics with USP1 cDNA into CNE1 cells. Compared to the NC and control cells, the CCK-8 and wound-healing assays showed that the reversed regulation of USP1 could partially abolish the effect of miR-375 on tumor proliferation. Western blot analysis revealed that after USP1 overexpression, the levels of CCS-3, c-Myc, Bad, Bcl-2, and Bax were significantly reversed compared to cells that were only transfected with miR-375 mimics. Meanwhile, the levels of E-cadherin, N-cadherin, Snail, and vimentin were also significantly reversed compared to cells that were only transfected with miR-375 mimics. These experimental data demonstrated that USP1 overexpression could reverse the miR-375-mediated effects on NPC cells in vitro.

\section{USP1 regulation of NPC cell viability and invasion by activation of the PI3K/AKT signaling}

USP1 has been shown to de-ubiquitinate Akt and subsequently inhibit PI3K signaling in muscle during prolonged starvation[19]. Therefore, the effects of USP1 expression on regulation of the PI3K signaling were evaluated using a PI3K inhibitor (S2793). USP1 cDNA was first transfected into NCNE1 cells, which were then treated with or without S2793. Compared to the control group, USP1 overexpression significantly promoted tumor cell migration and invasion, but inhibited tumor cell apoptosis, whereas treatment with S2739 was able to reverse these events, even after USP1 overexpression (Fig. 9A-C). Western blot data also showed that the expression of USP1, Akt, c-Myc, and PI3K in cells with overexpressed USP1 was significantly higher compared to the control group, although S2793 treatment alone was not able to significantly reverse their expression in NPC cells (Fig. 9E). In contrast, the protein levels of PI3K and Akt were significantly reduced following S2793 treatment of USP1 cDNA-transfected cells, indicating that the activation of the PI3K/Akt pathway induced by USP1 was significantly inhibited by S2793 treatment. Overall, these data suggest that USP1 was able to upregulate PI3K/AKT signaling (Fig. 9D).

\section{Discussion}

In the current study, bioinformatical analysis was performed on DE-miRNAs in NPC tissues vs. normal mucosae, which led to the identification of potential miRNA target genes. There were numerous DE-miRNAs in NPC tissues and focus was placed on down-regulated miR-375 and up-regulated miR-21 in NPC cells. miR-375 regulates 78 central genes, while miR-21 regulates 168 central genes. Indeed, reduced miR-375 was previously shown to be associated with the development of hepatocellular carcinoma [20], hepatomas[21], oral squamous cell carcinoma [22], esophageal cancer[23], non-small cell lung cancer[24], and NPC tumorigenesis [3; 25]. Next, in vitro experiments were 
performed to confirm the anti-NPC activity and the potential target gene USP1. miR-375 was found to play an essential role in NPC tumorigenesis by targeting USP1 expression and PI3K signaling.

Furthermore, the analysis using TargetScan and Starbase tools confirmed that USP1 is likely a target of miR-375. Experimental data confirmed that USP1 expression was reduced following miR-375 overexpression in NPC cells. Meanwhile, the luciferase reporter assay verified that miR-375 was able to bind to the USP1 3'-UTR. miR-375 overexpression downregulated USP1 expression and negatively regulated USP1-mediated NPC cell migration, invasion, and apoptosis in vitro. In addition, the rescue experiments by co-transfection of miR-375 mimics with USP1 cDNA into CNE1 cells confirmed that USP1 overexpression was able to reverse the effect of miR-375 on NPC cell migration, invasion, apoptosis, and viability.

Indeed, previous studies showed that different miRNAs could target USP proteins as a potential strategy in cancer therapy[26; 27; 28]. USP1, a member of the ubiquitin-specific processing (UBP) family of proteases that is a deubiquitinating enzyme (DUB) with His and Cys domains, is known to play a role in protein ubiquitination and is believed to be essential for maintenance of cellular protein levels, apoptosis, DNA repair, and cell motility [29; 30; 31; $32 ; 33 ; 34$ ]. Importantly, the effects of ubiquitination lead to the suppression or progression of tumorigenic pathways in certain contexts of cell states[35]. For example, previous studies have shown that USP1 was an underlying target in hepatocellular carcinoma therapy [36; 37] and played a pivotal role in the development of non-small-cell lung cancer [38] and ovarian cancer[39]. Nevertheless, the underlying molecular progression by which USP1 suppressed NPC progression remains unknown[40]. In the current study, the analysis using data from the Oncomine Research Edition database[41] provided evidence showing that the level of USP1 mRNA was significantly upregulated in several tumor types[40], while the analysis of the data presented in this study indicates that USP1 may promote NPC development and progression (such as enhancing tumor cell migration and invasion).

In addition, the Akt pathway is known to be involved in cell survival and apoptosis [42; 43]; however, PI3K/Akt signaling was reported to be altered by miR-375[25]. Moreover, USP1 has been shown to induce tumor progression by regulation of Akt activity in lung cancer [19] and lymphoblastic leukemia [24]. In the current study, USP1 upregulation could influence the deubiquitination level of Akt, which in turn affects PI3K activity. When NPC cells were treated with S2793 to inhibit the PI3K pathway, the effects of USP1 overexpression in NPC cells were reversed. However, additional studies are needed to clarify their exact link and precise signaling in the regulation of NPC cell behaviors.

Indeed, the current study does have some limitations. For example, the influence of other non-coding RNAs (IncRNAs and circRNAs) on NPC tumorigenesis was not explored. Moreover, these data regarding miR-375 were not verified in vivo. The novelty of the current study involves discovering the complex mechanism of USP1 regulation by miR-375 and their interactions potentially affecting NPC development and metastasis. Meanwhile, it was further demonstrated that an interaction between miR-375 and USP1 affected PI3K-Akt signaling in NPC, which is also novel.

\section{Conclusions}

Numerous DE-miRNAs were found during NPC development. Among them, miR-375 was downregulated and miR-21 was upregulated. Downregulated miR-375 expression led to USP1 upregulation in NPC, which in turn activated $\mathrm{PI} 3 \mathrm{~K} /$ Akt signaling and promoted NPC cell migration and invasion, but inhibited NPC cell apoptosis. Thus, future study of induced miR-375 expression may represent a novel therapeutic approach for the treatment of NPC patients.

\section{Declarations}




\section{Ethics approval and consent to participate}

The study was approved by the Ethical Review Committee of the Third Affiliated Hospital of Wenzhou Medical University (202010211603000390417)

Availability of data and materials

All data can generated or used during the study appear in the submitted article.

Consent for publication

Written informed consent for publication was obtained from all participants.

\section{Conflict of interest statement}

The authors declared that there is no conflict of interest in this work.

\section{Funding}

Wenzhou Science and Technology Bureau (Y2020737)

Ruian Science and Technology Bureau (\#MS2019008)

\section{Author contribution}

Xu Jiayuan conceived and designed the experiments; Xu Jiayuan and Li Bangliang prepared the manuscript; Song Wei, Cao Longhe and Zhu Chansai performed the experiments; and Lin Sen analyzed the data.

\section{Acknowledgements}

The authors would like to thank Wenzhou Science and Technology Bureau and Ruian Science and Technology Bureau for financial support. This study was supported in part by a grant from the Wenzhou Science and Technology Bureau (\#Y2020737) and Ruian Science and Technology Bureau (\#MS2019008).

\section{References}

1. Bray, F., Ferlay, J., Soerjomataram, I., Siegel, R., Torre, L., \& Jemal, A. J. C. a. c. j. f. c. (2018). Global cancer statistics 2018: GLOBOCAN estimates of incidence and mortality worldwide for 36 cancers in 185 countries. 68(6), 394-424. doi:10.3322/caac.21492

2. Erratum: Global cancer statistics 2018: GLOBOCAN estimates of incidence and mortality worldwide for 36 cancers in 185 countries. \%J CA: a cancer journal for clinicians. (2020). 70(4), 313. doi:10.3322/caac.21609

3. Chen, Y., Chan, A., Le, Q., Blanchard, P., Sun, Y., \& Ma, J. J. L. (2019). Nasopharyngeal carcinoma. 394(10192), 6480. doi:10.1016/s0140-6736(19)30956-0

4. Wee, J., Ha, T., Loong, S., \& Qian, C. J. C. j. o. c. (2010). Is nasopharyngeal cancer really a "Cantonese cancer"? , 29(5), 517-526. doi:10.5732/cjc.009.10329

5. Lo, A., Lo, K., Ko, C., Young, L., \& Dawson, C. J. T. J. o. p. (2013). Inhibition of the LKB1-AMPK pathway by the Epstein-Barr virus-encoded LMP1 promotes proliferation and transformation of human nasopharyngeal epithelial cells. 230(3), 336-346. doi:10.1002/path.4201 
6. Lo, K., Chung, G., \& To, K. J. S. i. c. b. (2012). Deciphering the molecular genetic basis of NPC through molecular, cytogenetic, and epigenetic approaches. 22(2), 79-86. doi:10.1016/j.semcancer.2011.12.011

7. Li, Y., Chung, G., Lui, V., To, K., Ma, B., Chow, C., . . Lo, K. J. N. c. (2017). Exome and genome sequencing of nasopharynx cancer identifies NF-KB pathway activating mutations. 8, 14121. doi:10.1038/ncomms14121

8. Khanna, R., Moss, D., \& Gandhi, M. J. N. c. p. O. (2005). Technology insight: Applications of emerging immunotherapeutic strategies for Epstein-Barr virus-associated malignancies. 2(3), 138-149. doi:10.1038/ncponc0107

9. Ma, C., Nong, K., Wu, B., Dong, B., Bai, Y., Zhu, H., . . CR, c. c. r. (2014). miR-212 promotes pancreatic cancer cell growth and invasion by targeting the hedgehog signaling pathway receptor patched-1. 33, 54.

doi:10.1186/1756-9966-33-54

10. Yang, S., Wang, M., Yang, L., Li, Y., Ma, Y., Peng, X., . . therapy. (2020). MicroRNA-375 Targets ATG14 to Inhibit Autophagy and Sensitize Hepatocellular Carcinoma Cells to Sorafenib. 13, 3557-3570. doi:10.2147/ott.S247655

11. Cheng, Q., Li, Q., Xu, L., \& Jiang, H. J. M. m. r. (2021). Exosomal microRNA-301a-3p promotes the proliferation and invasion of nasopharyngeal carcinoma cells by targeting BTG1 mRNA. 23(5). doi:10.3892/mmr.2021.11967

12. Jiang, L., Zhang, Y., Li, B., Kang, M., Yang, Z., Lin, C., . . Wu, F. J. C. s. (2021). miRNAs derived from circulating small extracellular vesicles as diagnostic biomarkers for nasopharyngeal carcinoma. doi:10.1111/cas.14883

13. Zhou, X., Lin, Y., Chen, Y., Wang, L., Peng, X., Liao, J., . . Cai, L. J. J. o. c. p. (2021). Epstein-Barr virus (EBV) encoded microRNA BART 8-3p drives radioresistance-associated metastasis in nasopharyngeal carcinoma. doi:10.1002/jcp.30320

14. Chandrashekar, D., Bashel, B., Balasubramanya, S., Creighton, C., Ponce-Rodriguez, I., Chakravarthi, B., \& Varambally, S. J. N. (2017). UALCAN: A Portal for Facilitating Tumor Subgroup Gene Expression and Survival Analyses. 19(8), 649-658. doi:10.1016/j.neo.2017.05.002

15. Li, J., Liu, S., Zhou, H., Qu, L., \& Yang, J. J. N. a. r. (2014). starBase v2.0: decoding miRNA-ceRNA, miRNA-ncRNA and protein-RNA interaction networks from large-scale CLIP-Seq data. 42, D92-97. doi:10.1093/nar/gkt1248

16. Agarwal, V., Bell, G., Nam, J., \& Bartel, D. J. e. (2015). Predicting effective microRNA target sites in mammalian mRNAs. 4. doi:10.7554/eLife.05005

17. El-Naggar, A. J. C. t. o. i. o. (2017). What Is New in the World Health Organization 2017 Histopathology Classification? , 18(7), 43. doi:10.1007/s11864-017-0469-x

18. Huang, H., Lin, Y., Li, J., Huang, K., Shrestha, S., Hong, H., . . Huang, H. J. N. a. r. (2020). miRTarBase 2020: updates to the experimentally validated microRNA-target interaction database. 48, D148-D154.

doi:10.1093/nar/gkz896

19. Goldbraikh, D., Neufeld, D., Eid-Mutlak, Y., Lasry, I., Gilda, J., Parnis, A., \& Cohen, S. J. E. r. (2020). USP1 deubiquitinates Akt to inhibit PI3K-Akt-FoxO signaling in muscle during prolonged starvation. 21(4), e48791. doi:10.15252/embr.201948791

20. Xu, R., Yin, S., Zheng, M., Pei, X., Ji, X. J. D. d., \& sciences. (2021). Circular RNA circZFR Promotes Hepatocellular Carcinoma Progression by Regulating miR-375/HMGA2 Axis. doi:10.1007/s10620-020-06805-2

21. Wang, C., Luo, J., Chen, Z., Ye, M., Hong, Y., Liu, J., . . sciences. (2021). MiR-375 Impairs the Invasive Capabilities of Hepatoma Cells by Targeting HIF1a Under Hypoxia. 66(2), 493-502. doi:10.1007/s10620-020-06202-9

22. Sun, Y., Chen, L., \& Pan, L. J. O. I. (2021). IncRNA UASR1 is overexpressed in oral squamous cell carcinoma and regulates cancer cell proliferation by regulating miR-375/JAK2 axis. 21(4), 288. doi:10.3892/ol.2021.12549 
23. Wu, W., Zhang, Y., Li, X., Wang, X., \& Yuan, Y. J. C. g. t. (2020). miR-375 inhibits the proliferation, migration and invasion of esophageal squamous cell carcinoma by targeting XPR1.

doi:10.2174/1566523220666201229155833

24. Jin, Y., Su, Z., Sheng, H., Li, K., Yang, B., \& Li, S. J. N. (2021). Circ_0086720 knockdown strengthens the radiosensitivity of non-small cell lung cancer via mediating the miR-375/SPIN1 axis. 68(1), 96-107. doi:10.4149/neo_2020_200331N333

25. Jia-Yuan, X., Wei, S., Fang-Fang, L., Zhi-Jian, D., Long-He, C., \& Sen, L. J. B. r. i. (2020). miR-375 Inhibits the Proliferation and Invasion of Nasopharyngeal Carcinoma Cells by Suppressing PDK1. 2020, 9704245. doi:10.1155/2020/9704245

26. Cai, J., Liu, T., Huang, P., Yan, W., Guo, C., Xiong, L., . . communications, b. r. (2017). USP39, a direct target of microRNA-133a, promotes progression of pancreatic cancer via the AKT pathway. 486(1), 184-190. doi:10.1016/j.bbrc.2017.03.025

27. Huang, L., Hu, C., Cao, H., Wu, X., Wang, R., Lu, H., . . pharmacology. (2018). MicroRNA-29c Increases the Chemosensitivity of Pancreatic Cancer Cells by Inhibiting USP22 Mediated Autophagy. 47(2), 747-758. doi:10.1159/000490027

28. Xu, G., Cai, J., Wang, L., Jiang, L., Huang, J., Hu, R., \& Ding, F. J. E. c. r. (2018). MicroRNA-30e-5p suppresses nonsmall cell lung cancer tumorigenesis by regulating USP22-mediated Sirt1/JAK/STAT3 signaling. 362(2), 268278. doi:10.1016/j.yexcr.2017.11.027

29. Vucic, D., Dixit, V., \& Wertz, I. J. N. r. M. c. b. (2011). Ubiquitylation in apoptosis: a post-translational modification at the edge of life and death. 12(7), 439-452. doi:10.1038/nrm3143

30. Nakayama, K., \& Nakayama, K. J. N. r. C. (2006). Ubiquitin ligases: cell-cycle control and cancer. 6(5), $369-381$. doi:10.1038/nrc1881

31. Geng, F., Wenzel, S., \& Tansey, W. J. A. r. o. b. (2012). Ubiquitin and proteasomes in transcription. 81, $177-201$. doi:10.1146/annurev-biochem-052110-120012

32. Schaefer, A., Nethe, M., \& Hordijk, P. J. T. B. j. (2012). Ubiquitin links to cytoskeletal dynamics, cell adhesion and migration. 442(1), 13-25. doi:10.1042/bj20111815

33. Ulrich, H., \& Walden, H. J. N. r. M. c. b. (2010). Ubiquitin signalling in DNA replication and repair. 11(7), $479-489$. doi:10.1038/nrm2921

34. Deng, L., Meng, T., Chen, L., Wei, W., Wang, P. J. S. t., \& therapy, t. (2020). The role of ubiquitination in tumorigenesis and targeted drug discovery. 5(1), 11. doi:10.1038/s41392-020-0107-0

35. Chen, Y., Wu, H., \& Shen, X. J. C. I. (2016). The ubiquitin-proteasome system and its potential application in hepatocellular carcinoma therapy. 379(2), 245-252. doi:10.1016/j.canlet.2015.06.023

36. Li, Y., Xu, Y., Gao, C., Sun, Y., Zhou, K., Wang, P., . . Yang, X. J. F. i. o. (2020). USP1 Maintains the Survival of Liver Circulating Tumor Cells by Deubiquitinating and Stabilizing TBLR1. 10, 554809. doi:10.3389/fonc.2020.554809

37. Zhao, Y., Xue, C., Xie, Z., Ouyang, X., \& Li, L. J. C. p. (2020). Comprehensive analysis of ubiquitin-specific protease 1 reveals its importance in hepatocellular carcinoma. 53(10), e12908. doi:10.1111/cpr.12908

38. Sourisseau, T., Helissey, C., Lefebvre, C., Ponsonnailles, F., Malka-Mahieu, H., Olaussen, K., . . Soria, J. J. C. c. (2016). Translational regulation of the mRNA encoding the ubiquitin peptidase USP1 involved in the DNA damage response as a determinant of Cisplatin resistance. 15(2), 295-302. doi:10.1080/15384101.2015.1120918

39. Sonego, M., Pellarin, I., Costa, A., Vinciguerra, G., Coan, M., Kraut, A., . . Baldassarre, G. J. S. a. (2019). USP1 links platinum resistance to cancer cell dissemination by regulating Snail stability. 5(5), eaav3235. 
doi:10.1126/sciadv.aav3235

40. García-Santisteban, I., Peters, G., Giovannetti, E., \& Rodríguez, J. J. M. c. (2013). USP1 deubiquitinase: cellular functions, regulatory mechanisms and emerging potential as target in cancer therapy. 12, 91. doi:10.1186/14764598-12-91

41. Rhodes, D., Yu, J., Shanker, K., Deshpande, N., Varambally, R., Ghosh, D., . . Chinnaiyan, A. J. N. (2004). ONCOMINE: a cancer microarray database and integrated data-mining platform. 6(1), 1-6. doi:10.1016/s14765586(04)80047-2

42. Guo, B., Wang, W., Zhao, Z., Li, Q., Zhou, K., Zhao, L., . . Huang, C. J. P. o. (2017). Rab14 Act as Oncogene and Induce Proliferation of Gastric Cancer Cells via AKT Signaling Pathway. 12(1), e0170620. doi:10.1371/journal.pone.0170620

43. Kim, C., Tambe, Y., Mukaisho, K., Sugihara, H., Kawauchi, A., \& Inoue, H. J. O. I. (2016). Akt-dependent activation of Erk by cyclin D1b contributes to cell invasiveness and tumorigenicity. 12(6), 4850-4856.

doi:10.3892/ol.2016.5286

\section{Figures}




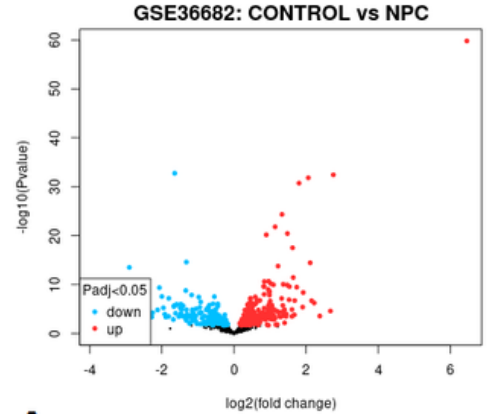

A
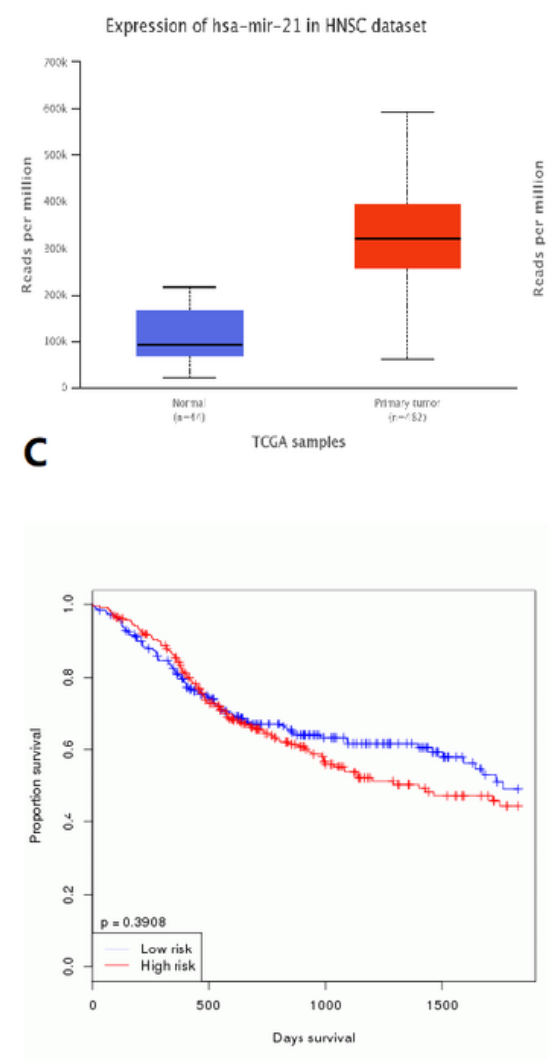

E miR-21

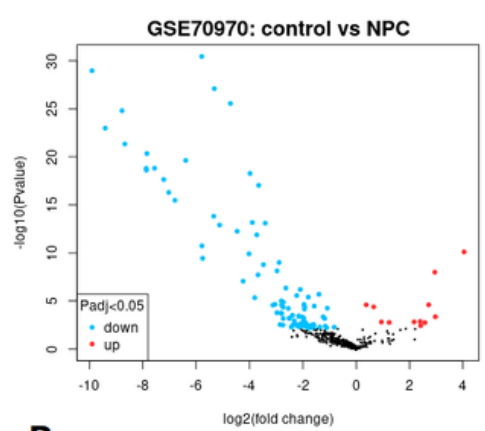

B
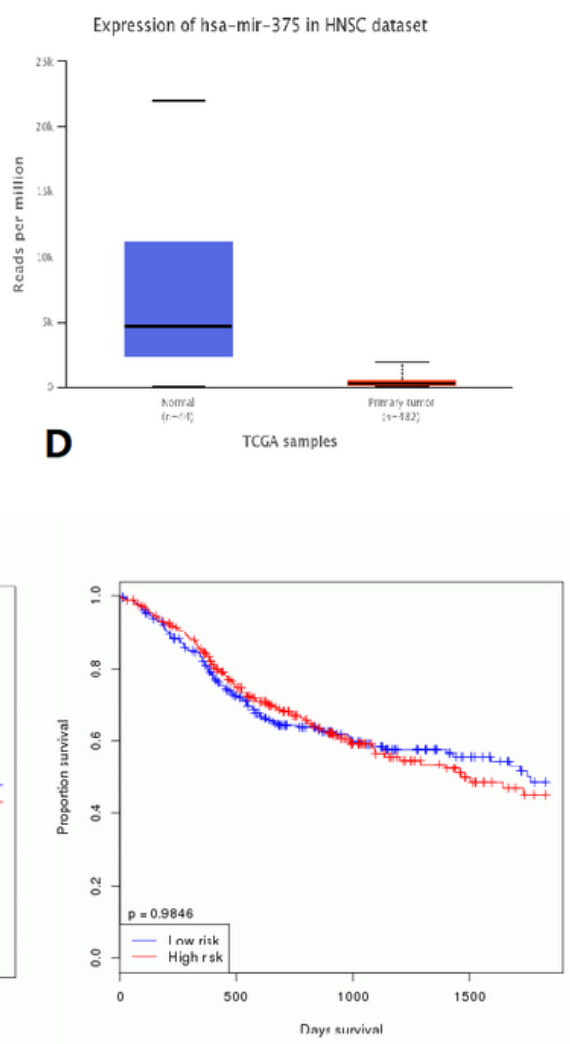

F $\quad$ miR-375

Figure 1

Identification of differentially expressed microRNAs (DE-miRNAs) using data from the Gene Expression Omnibus (GEO) database using NPC-DEM analysis. (A) Volcano plot of GEO Series (GSE) 36682 dataset. (B) Volcano plot of GSE 70970 dataset. The blue dots represent downregulated miRNAs, while the red dots represent upregulated miRNAs in nasopharyngeal carcinoma (NPC) vs. normal tissue samples. (C and D) Expression of miR-375 and miR21 in tumor tissue vs. normal tissue. (E and F) Kaplan-Meier survival curves of NPC patients stratified by miR-375 and miR-21 expression. 
A

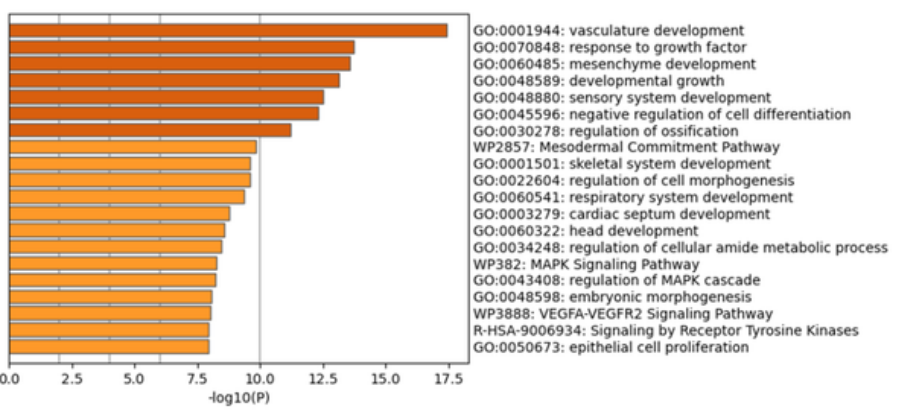

B
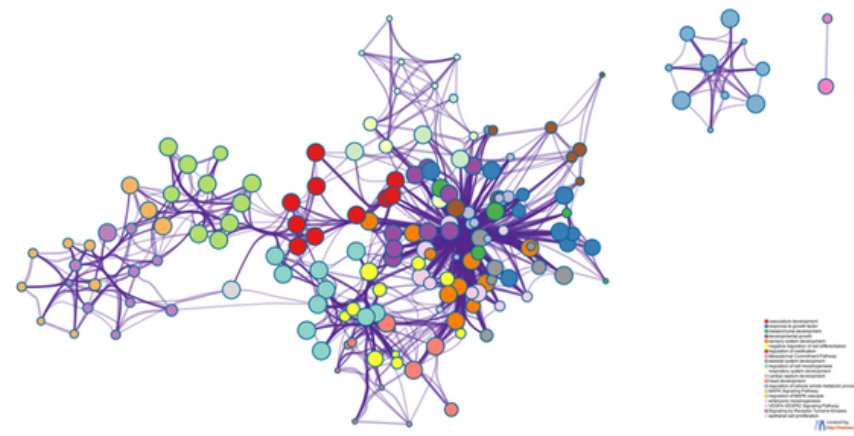

C

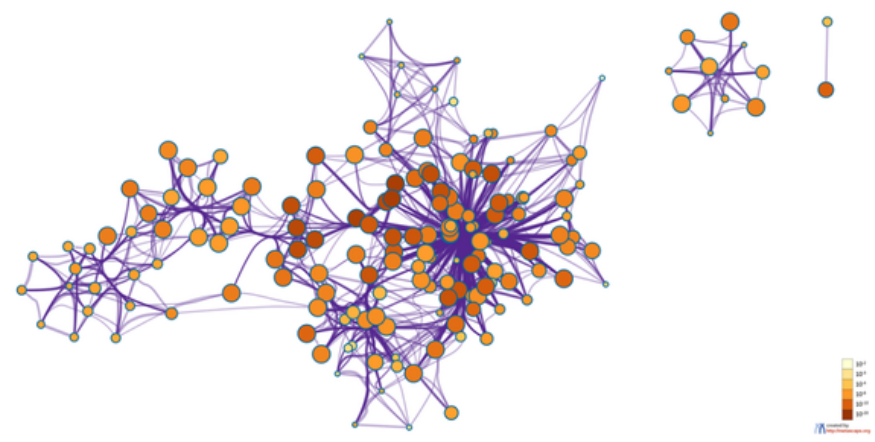

D

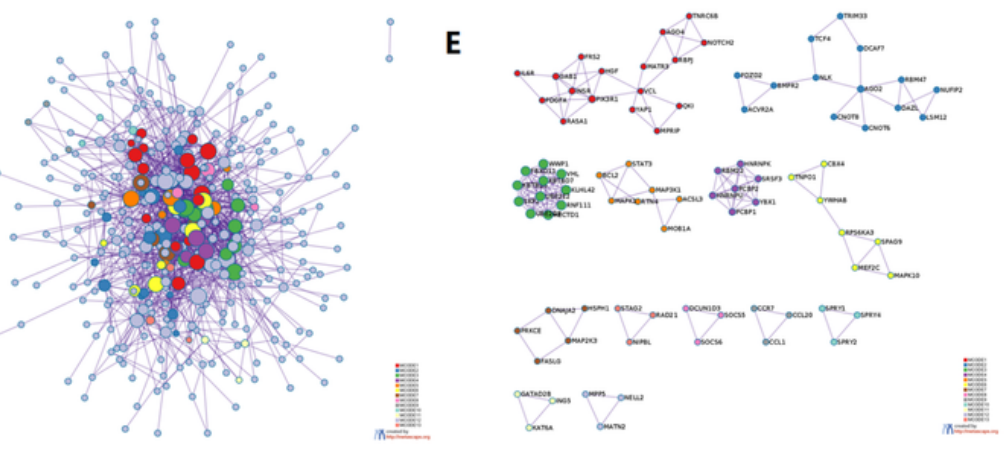

Figure 2

The gene ontology (GO) terms and gene pathway enrichment analysis of the predicted miR-375 and miR-21 target genes. (A) The GO terms. The data show the enriched biological process, cellular component, and molecular function of the target genes. (B and C) Pathway enrichment analysis of the target genes. (D and E) MCODE network. Each MCODE network is assigned a unique color. 


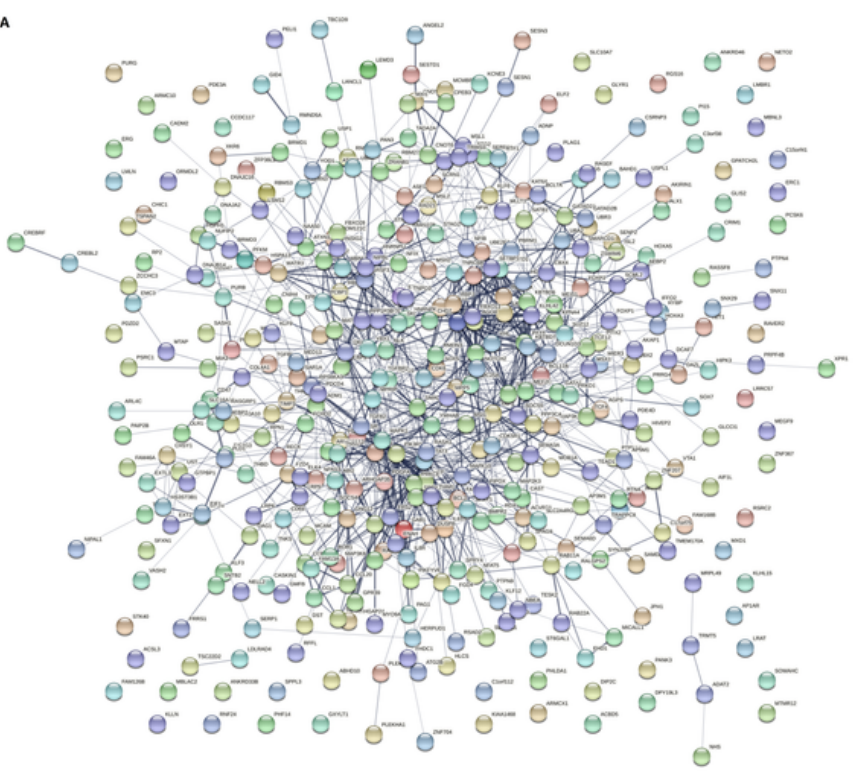

B

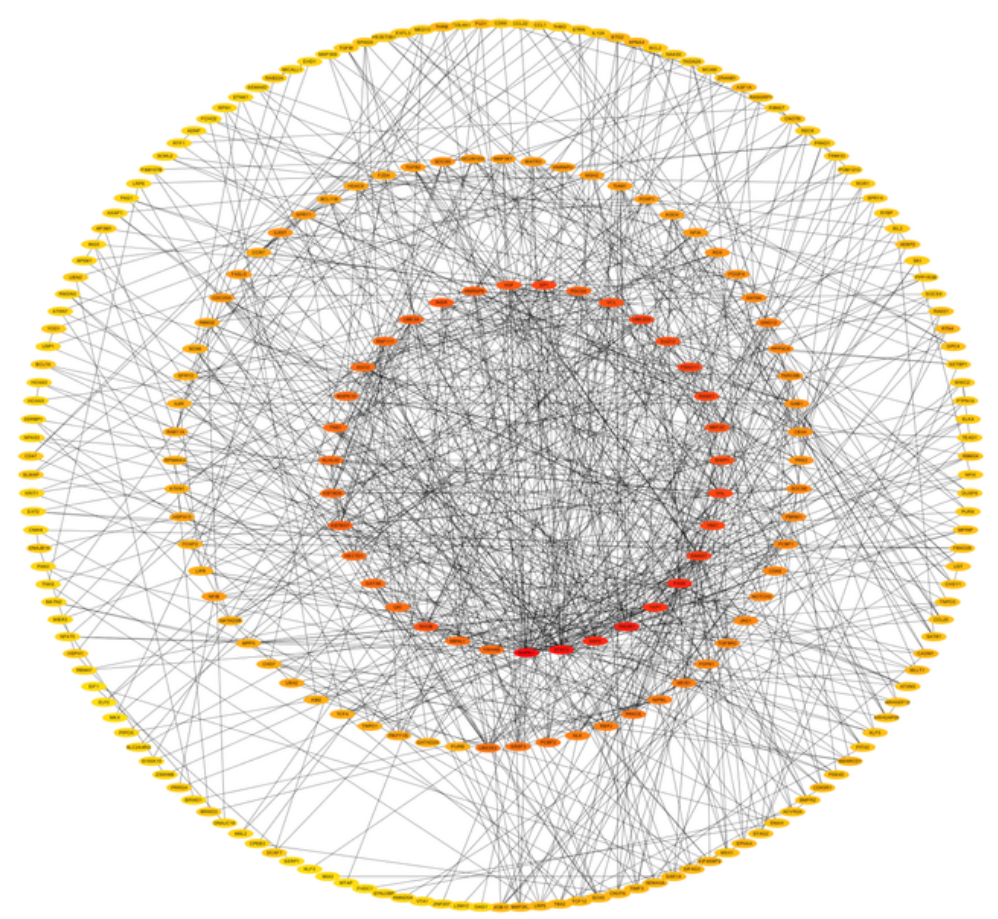

\section{Figure 3}

The protein-protein interaction (PPI) network. The data show the top 250 hub genes network and top 10 hub genes of miR-21 and miR-375 target genes (ranked by degree value). (A) PPI network of the target genes. (B) Hub genes identified in the PPI interaction (top 250). More important genes are represented by darker colors. 

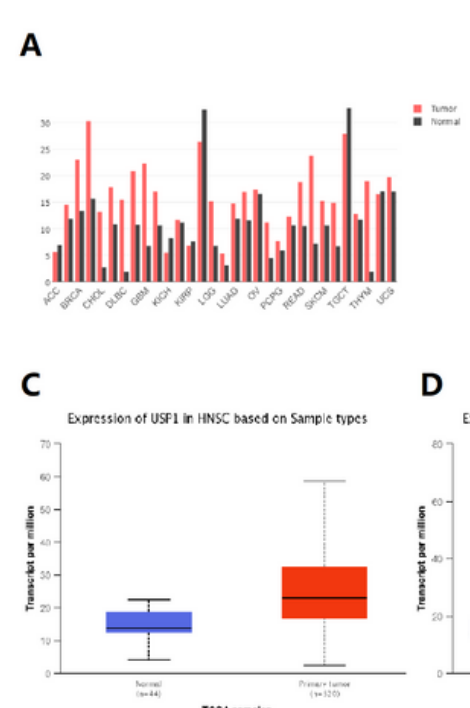

D

B

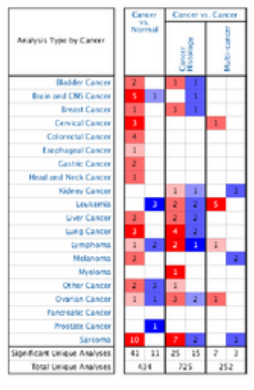

Expression of USP1 in HNSC based on tumor gradc

E

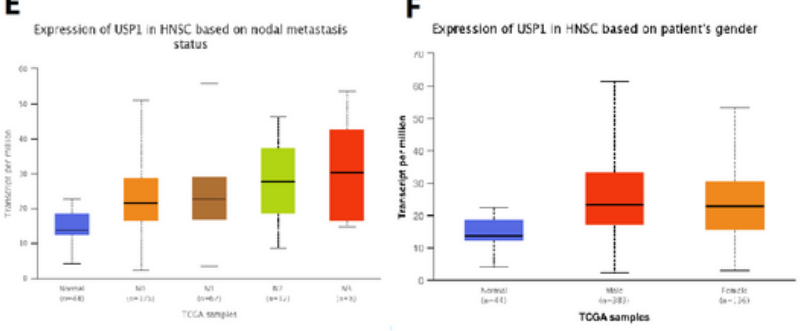

G

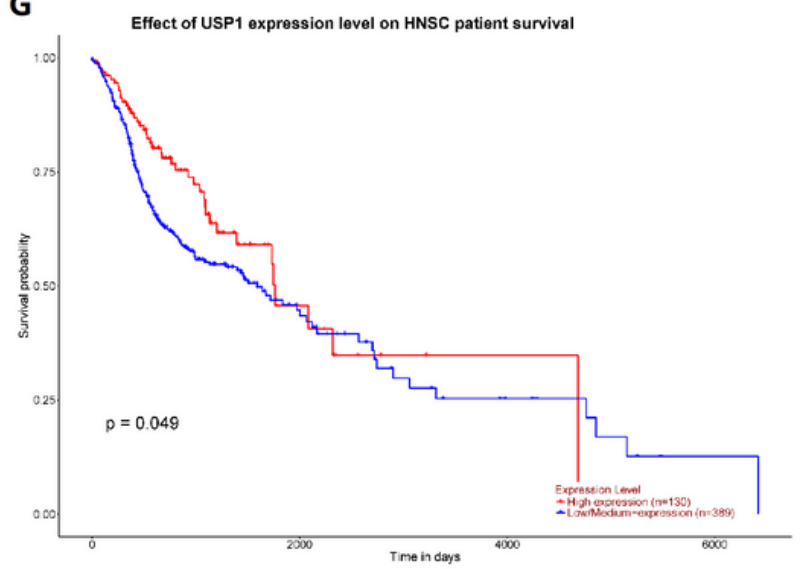

Figure 4

Ubiquitin-specific protease 1 (USP1) expression and association with cancer prognosis. (A and B) Level of USP1 expression in various cancers. (C-F) USP1 expression in head and neck squamous cell carcinoma (HNSSC; samples, tumor grade, metastasis and gender). (G) Kaplan-Meier curves of HNSSC patients stratified by USP1 expression. 
A

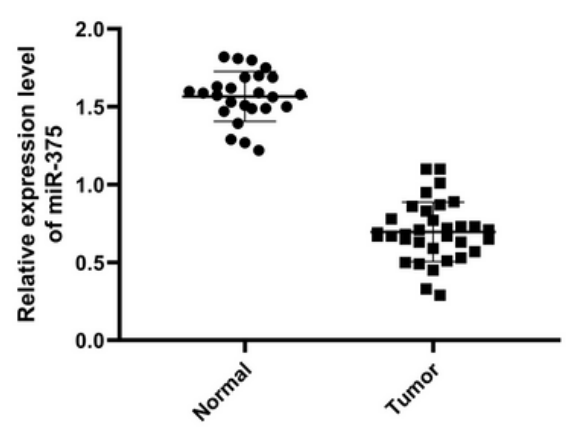

C

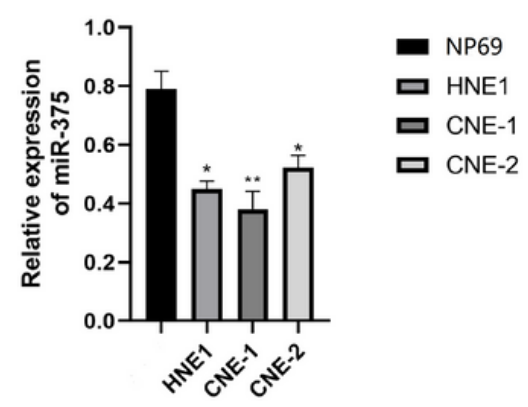

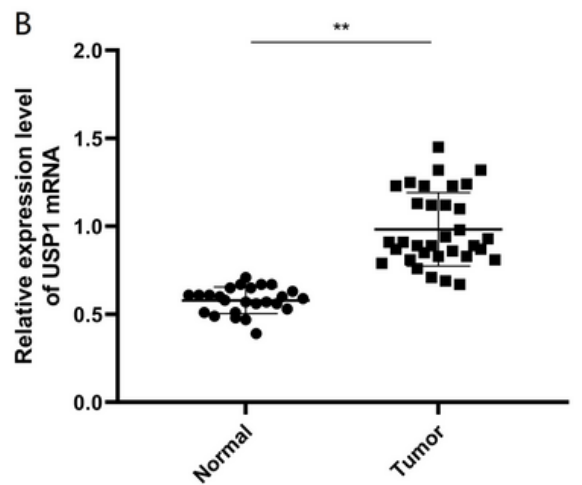

D
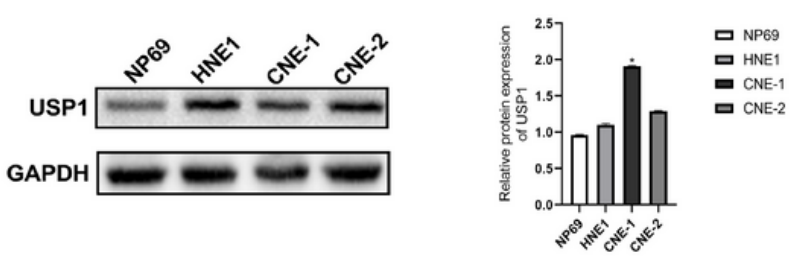

E
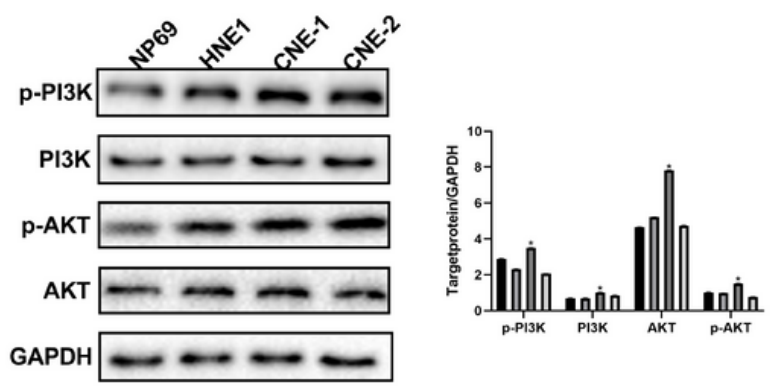

Figure 5

Expression of miR-375 and ubiquitin-specific protease 1 (USP1) in nasopharyngeal carcinoma (NPC) tissues and cell lines. (A) Quantitative reverse transcription-polymerase chain reaction (qRT-PCR) analysis of miR-375 levels in 25 pairs of primary NPC and adjacent normal tissues. (B) qRT-PCR analysis of USP1 mRNA in 25 pairs of primary NPC and adjacent normal tissues. (C) qRT-PCR analysis of miR-375 levels in three NPC cell lines and normal RBE cells. (D) Western blot analysis of USP1 protein in cell lines. (E) Western blot analysis of various proteins. ${ }^{*} p<0.05$ and ${ }^{*} p<$ 0.01 . 


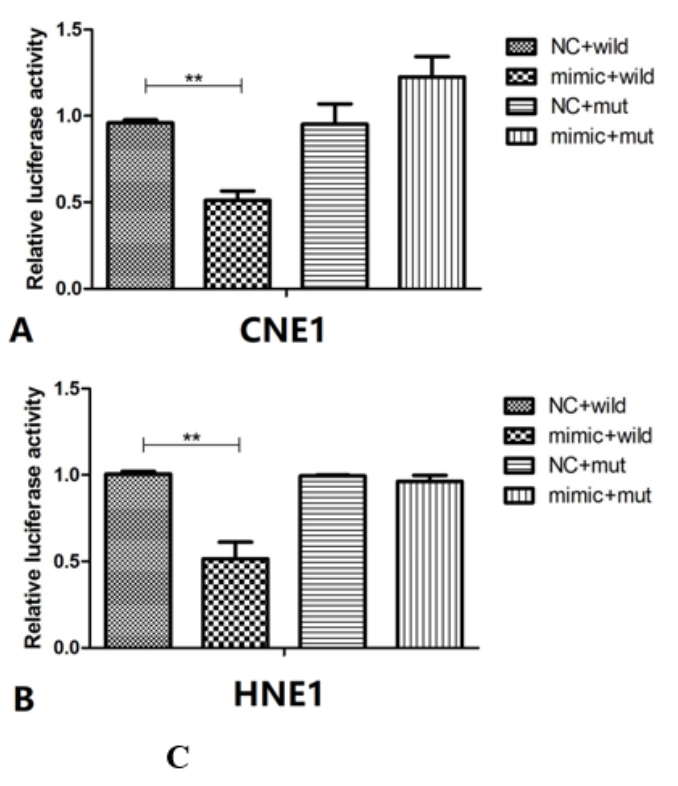

Position 219-225
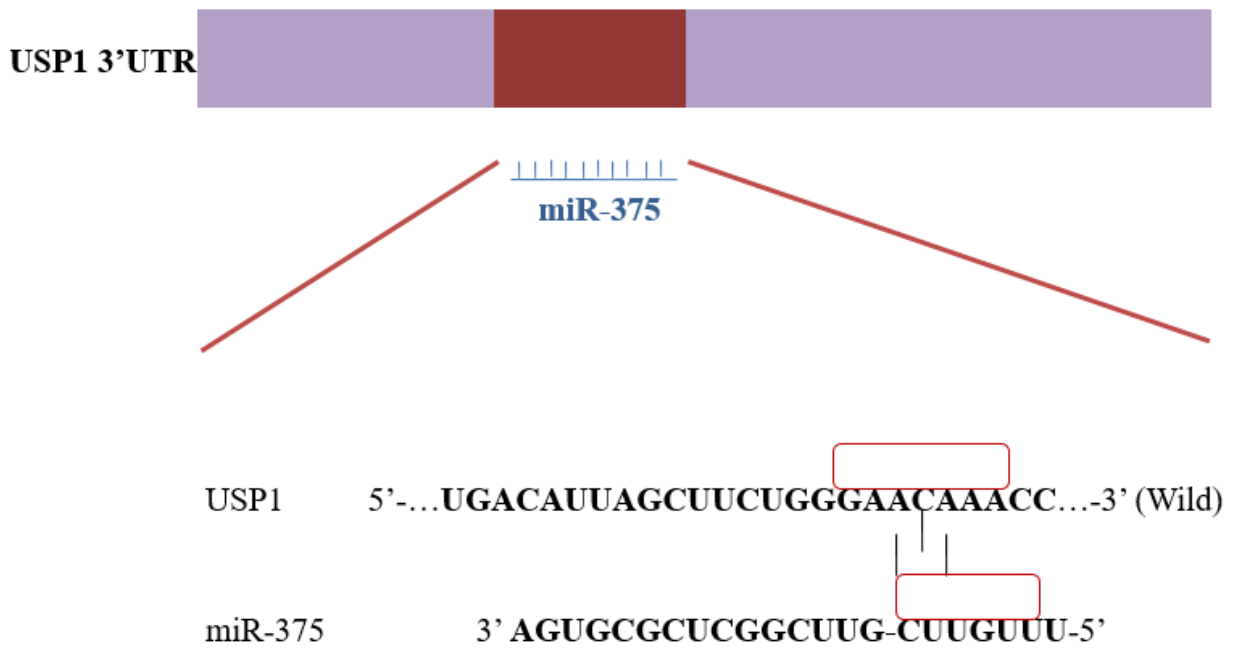

USP1 5 '-...UGACAUUAGCUUCUGGAGGUGCCCC...-3' (Mut)

\section{Figure 6}

miR-375 targets ubiquitin-specific protease 1 (USP1) expression. (A and B) Luciferase assay. The relative luciferase activity in CNE1 and HNE1 cells after co-transfection with wild type (wt) or mutant (mut) USP1 3'-untanslated region (UTR) reporter constructs together with miR-375 mimics and negative control (NC). (C) Bioinformatic prediction of the miR-375 binding sites to the USP1 3'-UTR. * $p<0.05$ and ${ }^{*} \mathrm{p}<0.01$. 


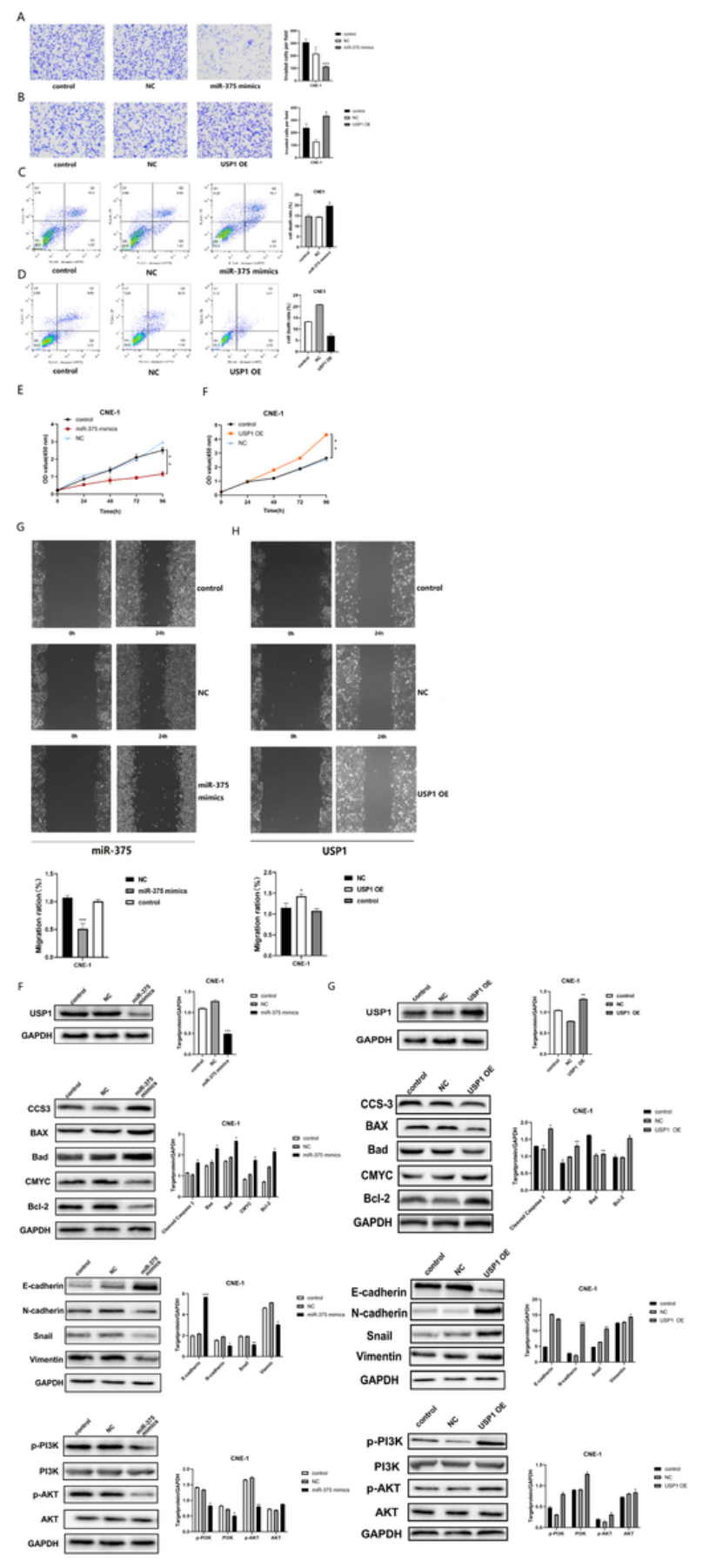

\section{Figure 7}

Effects of miR-375 and ubiquitin-specific protease 1 (USP1) expression in nasopharyngeal carcinoma (NPC) cells. (A) Transwell assay. miR-375 mimics inhibit NPC cell invasion. (B) Transwell assay. USP1 expression induces NPC cell invasion. (C) Flow cytometric assay. miR-375 mimics accelerated NPC cell apoptosis. (D) Flow cytometric assay. USP1 expression suppresses NPC cell apoptosis. (E) Cell viability cell counting kit-8 (CCK-8) assay. miR-375 recued NPC cell viability. (F) Cell viability CCK-8 assay. USP1 promotes NPC cell viability. (G and H) Wound-healing assay. miR-375 inhibits NPC cell migration, whereas USP1 expression promotes NPC cell migration. (I) Western blot analysis of proteins in miR-375 mimics and negative control (NC) group-transfected NPC cells. The graphs are quantified data. ${ }^{*} p<0.05$ and ${ }^{* *} p<0.01$. 
A
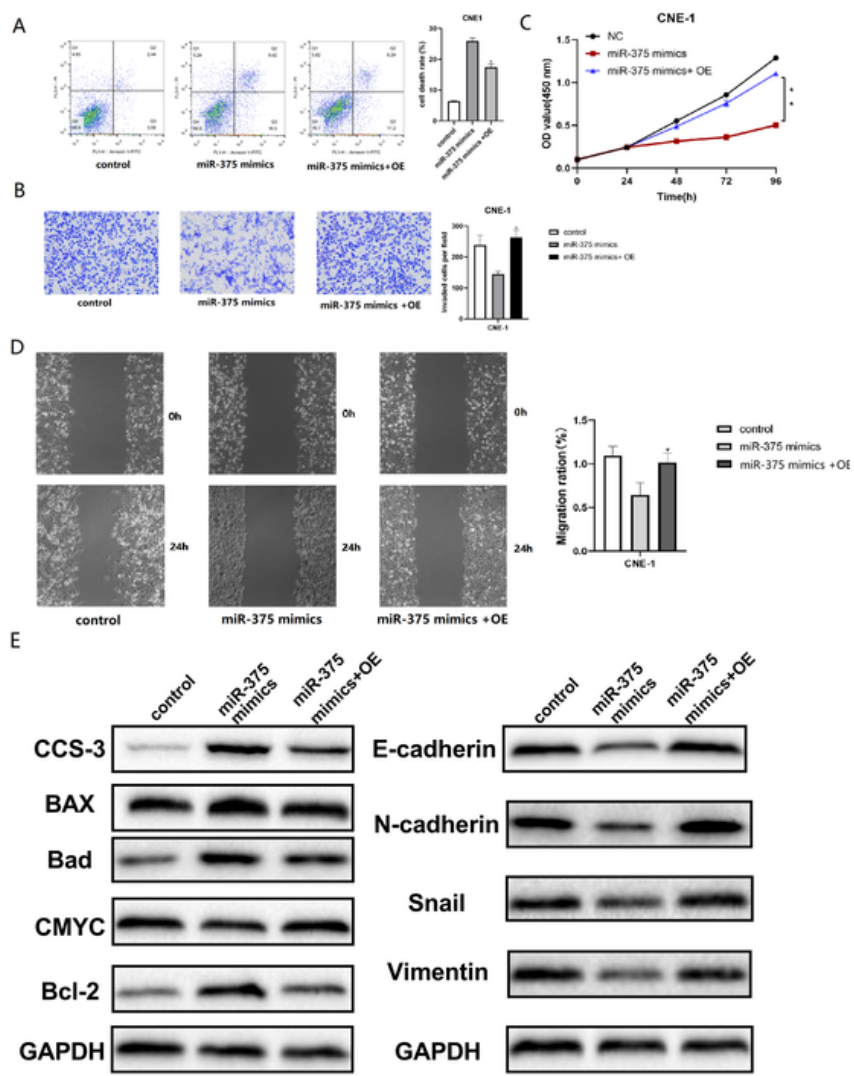

CNE-1
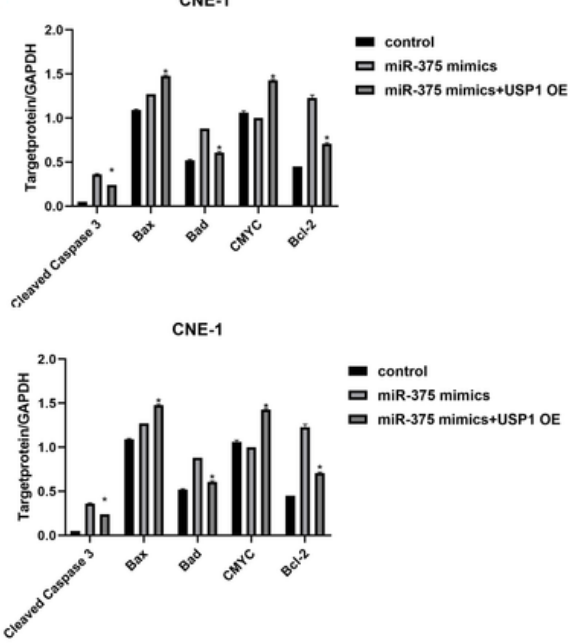

\section{Figure 8}

Effects of ubiquitin-specific protease 1 (USP1) overexpression to evaluate miR-375-mediated effects on nasopharyngeal carcinoma (NPC) cells. (A) Flow cytometric assay. Transfection of USP1-OE into miR-375transfected NPC cells inhibits NPC cell apoptosis. (B) Transwell assay. Transfection of USP1-OE into miR-375transfected NPC cells promotes NPC cell invasion capacity. (C) Cell viability cell counting kit-8 (CCK-8) assay. Transfection of USP1-OE into miR-375-transfected NPC cells reverses the effect of miR-375 mimics on cell viability. (D) Wound-healing assay. Transfection of USP1-OE into miR-375-transfected NPC cells promotes NPC cell migration. (E) Western-blot. The graphs are quantified data. ${ }^{*} p<0.05$ and ${ }^{* *} p<0.01$. 
A
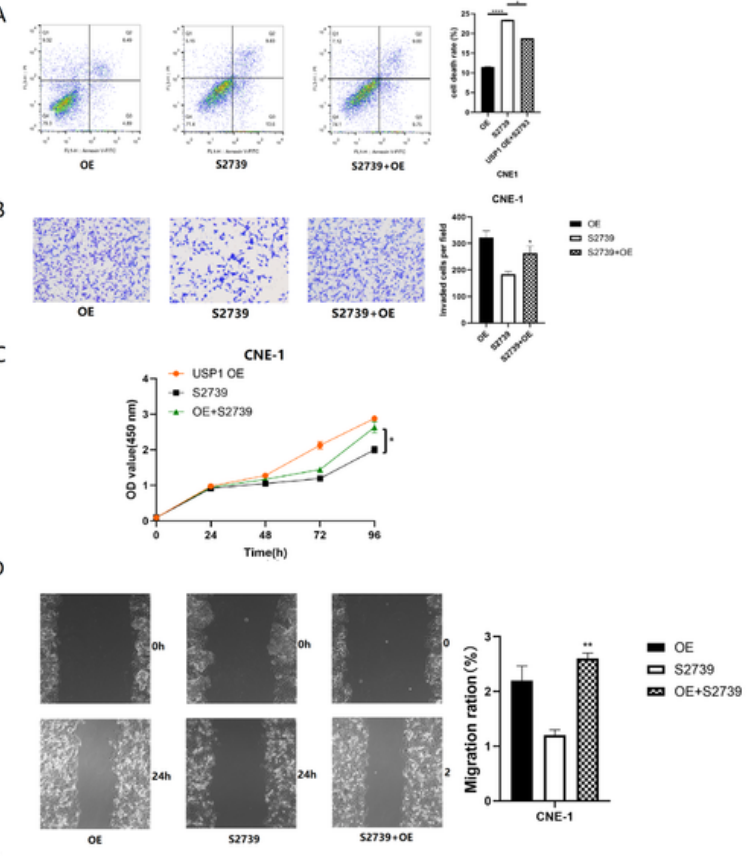

E
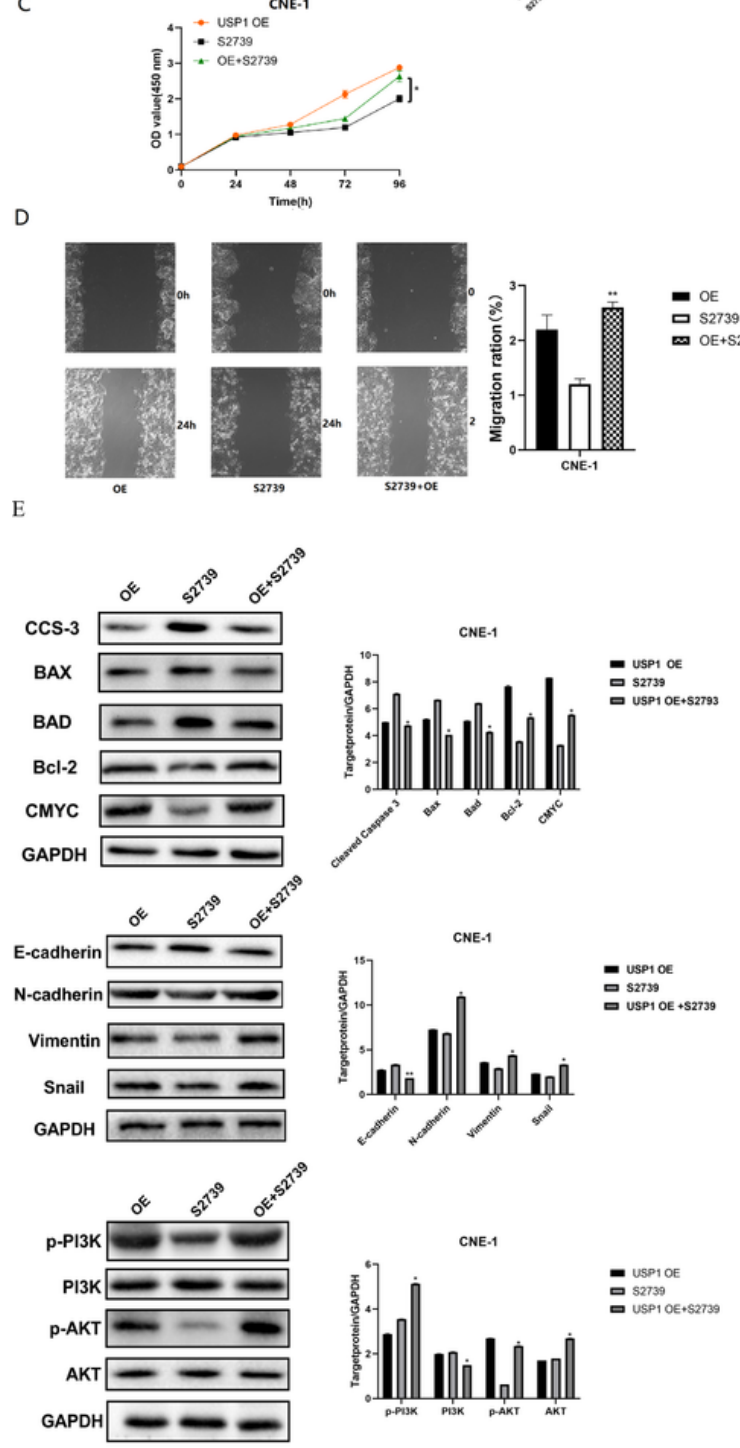

\section{Figure 9}

Inhibition of phosphoinositide 3-kinase (PI3K)/Akt signaling by ubiquitin-specific protease 1 (USP1), a target of miR375 in nasopharyngeal carcinoma (NPC) cells. (A) Flow cytometric assay. NPC cells were transfected with USP1 cDNA and then treated with or without S2739 and subjected to flow cytometric apoptosis assay. (B) Transwell assay. The duplicated cells were subjected to a Transwell invasion assay. (C) Transfection of USP1-OE reversed the effect of S2739 on cell growth. (D) Cell viability cell counting kit-8 (CCK-8) assay. The same treatment cells were subject to CCK-8 assay. (E) Western blot. NPC cells were transfected with USP1 cDNA and then treated with or without S2739 and subjected to western blot assay. The graphs were quantified data. ${ }^{*} p<0.05$ and ${ }^{*} p<0.01$. 